\title{
Sexing of postimplantation rat embryos in stored two- dimensional electrophoresis (2-DE) samples by polymerase chain reaction (PCR) of an Sry sequence
}

\author{
Atsuko Miyajima'1, Momoko Sunouchi'1, Katsuyoshi Mitsunaga², Yoko Yamakoshi ${ }^{3}$, \\ Ken Nakazawa ${ }^{1}$ and Makoto Usami ${ }^{1}$ \\ ${ }^{1}$ Division of Pharmacology, National Institute of Health Sciences, 1-18-1 Kamiyoga, Setagaya, Tokyo 158-8501, \\ Japan \\ ${ }^{2}$ Graduate School of Pharmaceutical Sciences, Toho University, 2-1-1 Miyama, Funabashi, Chiba 274-8510, Japan \\ ${ }^{3}$ Department of Radiology, Department of Chemistry, University of Pennsylvania, 231 South 34th Street, Philadelphia \\ PA 19104-6323, USA
}

(Received June 25, 2009; Accepted August 10, 2009)

\begin{abstract}
Proteomic analysis of developmental toxicity by two-dimensional electrophoresis (2$\mathrm{DE}$ ) may detect gender-related toxic effects in embryos without visible gender characteristics. In the present study, we explored sexing of rat embryo stored in frozen 2-DE samples by polymerase chain reaction (PCR) of a male-specific gene sequence, sex determining region Y (Sry). The embryo proper and yolk sac membrane at gestation day 11 from Wistar rats were used for stored embryonic 2-DE samples. The embryonic 2-DE samples were desalted and their total DNA was extracted. The Sry sequence in the extracted DNA was amplified by PCR and the product was analyzed by agarose gel electrophoresis. The embryos with the PCR product of Sry were determined as male, and those without the product were determined as female. It was concluded that stored embryonic 2-DE samples could be used for retrospective examination of gender-related effects in proteomic analysis of developmental toxicity.
\end{abstract}

Key words: Developmental toxicity, Embryo, PCR, Sexing, Sry, 2-DE

\section{INTRODUCTION}

It has been shown that some chemicals have gender differences in their developmental toxicities when examined in rat fetuses or neonates. Prenatal exposure to procarbazine on day 14 of gestation induced cleft palate and microgenia more frequently in males than in females of rat fetuses (Malek et al., 2003). It has been suggested that perinatal exposure to polychlorinated biphenyls affects behavior and cerebellar development of males more severely than those of females in rat neonates (Nguon et al., 2005). However, developmental toxicity studies of chemicals with early postimplantation rat embryos both in vivo and in vitro have often been performed irrespective to their gender. This is because there are no visible gender characteristics yet, although sex determination and gonadal differentiation begin around this developmental stage in rodent embryos (Hunter, 1995).

Recent advances in analytical techniques revealed gen- der differences related to birth defects in early postimplantation rodent embryos. For example, neural tube defects, a major congenital malformation, are more frequent in female embryos than in male ones as early as day 10.5 of gestation in p53-null mice (Chen et al., 2008). It is therefore likely that comprehensive biochemical and molecular analyses, such as proteomics by two-dimensional electrophoresis (2-DE), of early postimplantation rat embryos (Usami et al., 2007b), might detect gender-related toxic effects when the data is analyzed according to the embryonic gender.

The gender of rat embryos can be determined by polymerase chain reaction (PCR) of a sequence in Sry, a male-specific gene on the Y chromosome (Poletti et al., 1998), in DNA samples from the embryonic tissues, i.e., the embryo proper or yolk sac membrane. There are, however, no reported methods applicable to comprehensive proteomic analyses of early postimplantation rat embryos, where both embryo proper and yolk sac membrane are

Correspondence: Atsuko Miyajima (E-mail: miyajima@nihs.go.jp) 
used for 2-DE in order to examine tissue-specific responses (Usami et al., 2007a, 2008).

In the present study, we attempted sexing of postimplantation rat embryos stored in frozen 2-DE samples by PCR of an Sry sequence. Stored embryonic 2-DE samples were desalted with spin columns, and their DNA was extracted with an extraction kit. The extracted DNA was used for PCR. A sequence of beta actin gene (Actb) was also amplified simultaneously as a control. The embryos with the PCR product of Sry were determined as male, and those without the product were determined as female.

\section{MATERIALS AND METHODS}

\section{Collection of tissue samples}

Wistar rats (Crlj: WI, Charles River Laboratories Japan, Kanagawa, Japan) were used. Day 11 (plug day = day 0) in vivo or equivalent in vitro embryos cultured for 24 or $48 \mathrm{hr}$ (Usami and Ohno, 1996) were collected in Hanks' balanced salt solution. The embryo proper and yolk sac membrane from the embryos were washed three times with ice-cold buffer (10 mM Tris- $\mathrm{HCl}, \mathrm{pH} 7.0,150$ $\mathrm{mM} \mathrm{NaCl}$ ), and stored at $-80^{\circ} \mathrm{C}$ in $1.5 \mathrm{ml}$ Eppendorf tubes individually with a minimum amount of the buffer. Kidneys were removed from adult male and female rats for the preparation of male and female DNAs working as references. All the animal experiments were performed according to the guideline for animal experiments in National Institute of Health Sciences.

\section{Desalting of embryonic 2-DE samples}

Embryonic 2-DE samples prepared as follows and stored after the analyses at $-30^{\circ} \mathrm{C}$ were used. The embryo proper and yolk sac membrane of the day 11 embryos were lysed in $300 \mu 1$ /embryo of rehydration buffer, i.e., 2-DE lysis buffer, by pulsed sonication immediately after the addition of the buffer (Usami et al., 2007b). The 2-DE samples (20-50 $\mu \mathrm{l})$ were applied to spin columns (Micro Bio-Spin P-30 Tris, Bio-Rad, Hercules, CA, USA) and centrifuged at $1,000 \times \mathrm{g}$ for $4 \mathrm{~min}$ at $20^{\circ} \mathrm{C}$. The filtrates obtained were directly used for extraction of DNA.

\section{Extraction of DNA}

Total DNA was extracted from sample tissues with an extraction kit (DNeasy Blood \& Tissue Kits, QIAGEN, Valencia, CA, USA). Lysis buffer $(180 \mu \mathrm{l})$ of the extraction kit was added into $1.5 \mathrm{ml}$ Eppendorf tubes containing the desalted 2-DE sample $(20 \mu 1)$, entire embryo proper, entire yolk sac membrane or adult kidney (approximately $1 \mathrm{~mm}^{3}$ ), and thereafter the samples were processed according to the manufacturer's instruction to obtain 100 or $200 \mu 1$ of total DNA solutions. The concentration of extracted DNA was determined by absorbance at $260 \mathrm{~nm}$ (ND-1000 Spectrophotometer, NanoDrop Technologies, Wilmington, DE, USA). For determination of the detection limit of the PCR, extracted DNA was serially diluted with the extraction buffer prior to PCR analysis.

\section{PCR analysis of extracted DNA}

An Sry sequence was amplified by PCR with a forward primer, 5'- TAC AGC CTG AGG ACA TAT TA -3', and a reverse primer, 5'- GCA CTT TAA CCC TTC GAT GA -3', to yield a 317-bp product (Poletti et al., 1998). As a control, a sequence of an autosomal gene, beta actin gene (Actb, Chr. 12p11), was also amplified by PCR with a forward primer, 5'- AGC CAT GTA CGT AGC CAT CC -3', and a reverse primer, 5'- TGT GGT GGT GAA GCT GTA GC -3', the sequences of which were obtained from the NCBI UniSTS database (UniSTS: 270076, PMC102156P1), to yield a 220-bp product. PCR was performed in tubes containing $2 \mu \mathrm{l}$ of the extracted DNA sample and $23 \mu \mathrm{l}$ of a master mixture $(10 \mathrm{mM}$ Tris- $\mathrm{HCl}$, pH9.0, $50 \mathrm{mM} \mathrm{KCl,} \mathrm{0.1 \%} \mathrm{Triton} \mathrm{X-100,} 2 \mathrm{mM} \mathrm{MgCl}_{2}$, $200 \mu \mathrm{M}$ dATP, dGTP, dCTP and dTTP, 0.625U Ampli-Taq polymerase (Promega, Madison, WI, USA), and $0.2 \mu \mathrm{M}$ all of the above primers). PCR conditions were: denaturation at $95^{\circ} \mathrm{C}$ for $2 \mathrm{~min}$, followed by 35 cycles of amplification at $95^{\circ} \mathrm{C}$ for $1 \mathrm{~min}, 52^{\circ} \mathrm{C}$ for $1 \mathrm{~min}$ and $72^{\circ} \mathrm{C}$ for $1 \mathrm{~min}$, and then extension at $72^{\circ} \mathrm{C}$ for $5 \mathrm{~min}$ with a thermal cycler (GeneAmp PCR System 9700, Applied Biosystems, Foster City, CA, USA). For analysis of PCR products, the PCR mixture $(10 \mu \mathrm{l})$ diluted with loading buffer $(4 \mu \mathrm{l})$ was subjected to electrophoresis in a $3 \%$ agarose gel (NuSieve 3:1 Agarose, Biowhittaker Molecular Applications, Rocklane, ME, USA) for $70 \mathrm{~min}$ at 50 V. The gel was stained with SYBR Green I (FMC BioProducts, Rockland, ME, USA) for visualization of the products, and was photographed with a CCD camera system (DIANA, Raytest, Straubenhardt, Germany).

\section{RESULTS}

\section{Extraction of DNA from the embryonic samples}

The size of the embryos and concentrations of their extracted DNA are shown in Table 1. The embryos in the 2-DE samples include those treated with test chemicals in selected in vitro toxicity studies and therefore their sizes are smaller than those of usual day 11 embryos. In addition to the effects of test chemicals, varied sample volumes from the 2-DE samples caused large variations of the DNA concentrations. In the intact tissues, variations of the DNA concentrations also appeared to be large due 
Sexing of rat embryonic 2-DE samples

Table 1. Sizes and extracted DNA concentrations of day 11 rat embryos used for sexing

\begin{tabular}{lcc}
\hline & 2-DE sample & Intact tissue \\
\hline No. of embryos & 23 & 10 \\
Embryo size & & \\
$\quad$ Crown-rump length $(\mathrm{mm})^{\mathrm{a}}$ & $3.92 \pm 0.42$ & $4.32 \pm 0.25$ \\
$\quad$ Yolk sac diameter $(\mathrm{mm})^{\mathrm{a}}$ & $4.44 \pm 0.48$ & $4.89 \pm 0.38$ \\
Extracted DNA $(\mathrm{ng} / \mu \mathrm{l})^{\mathrm{a}}$ & & \\
$\quad$ Embryo proper $(\mathrm{ng} / \mu \mathrm{l})^{\mathrm{a}}$ & $36.6 \pm 14.3[5.12-58.9]$ & $80.4 \pm 32.5[32.5-154]$ \\
$\quad$ Calculated content ${ }^{\mathrm{b}}(\mu \mathrm{g})^{\mathrm{a}}$ & $48.3 \pm 23.7[7.68-88.4]$ & $11.7 \pm 5.57[6.22-20.4]$ \\
$\quad$ Yolk sac membrane $(\mathrm{ng} / \mu \mathrm{l})^{\mathrm{a}}$ & $6.29 \pm 3.48[2.28-13.9]$ & $50.4 \pm 35.4[15.0-111]$ \\
$\quad$ Calculated content ${ }^{\mathrm{b}}(\mu \mathrm{g})^{\mathrm{a}}$ & $8.44 \pm 5.79[2.99-20.8]$ & $6.32 \pm 2.97[3.00-11.1]$ \\
\hline
\end{tabular}

a: Mean \pm S.D. is shown. ${ }^{b}$ : DNA content per embryo calculated from the dilution factor.

Values in the brackets indicate ranges.

to the non-quantitative extraction procedure. In spite of their large concentration variations, these extracted DNA samples could be used for the PCR without adjustment of their concentrations. When DNA content per embryo was calculated from the dilution factor, the calculated content in the 2-DE samples and that of the yolk sac membrane in the intact tissues were comparable to the DNA content reported for rat embryos at similar developmental stages (Snell and Mullock, 1987), indicating that DNA was extracted effectively. The lower calculated content for the embryo proper in the intact tissues, on the other hand, is considered due to overload of the samples in the extraction of DNA.

\section{PCR of the Sry sequence in the extracted DNA}

PCR of the Sry sequence yielded a 317-bp product in the adult male kidney, but not in the female one, as a reference and the same product was observed in some embryos, which were determined as male (Fig. 1A). PCR of the $A c t b$ sequence yield a 220-bp product in all the samples, confirming successful PCR. Therefore, the embryos without the PCR product of Sry were determined as female. There were no differences between the products from the 2-DE samples and intact embryonic tissues, indicating validity of the present method in the analysis of 2-DE samples.

\section{Reliability and accuracy of the sexing}

Serial dilution of an extracted DNA from a male embryonic 2-DE sample showed that the PCR product of Sry could be detected together with that of Actb in the range as broad as from 0.5 to $50 \mathrm{ng} / \mu \mathrm{l} \mathrm{DNA}$ (Fig. 1B). At $0.05 \mathrm{ng} / \mu \mathrm{l}$ or less DNA, only the PCR product of Actb was detected and therefore embryonic gender might be misdetermined as female. However, DNA concentrations in the 2-DE samples from postimplantation rat embryos were sufficient for the detection of the PCR product of Sry as shown in Table 1.

As an index of accuracy of the sexing, embryonic genders determined by the embryo proper and yolk sac membrane samples were compared, since genetic genders are the same between them. In all the embryos of which both embryo proper and yolk sac membrane samples were used for sexing, their gender was consistent between the embryo proper and yolk sac membrane (Table 2). It was thus considered that embryonic genders determined by the present method were accurate.

\section{DISCUSSION}

The present results indicate that 2-DE samples stored after the analyses can be used for sexing of the rat embryos. This means that it is possible to examine gender-related effects retrospectively in proteomic analyses by 2-DE of postimplantation rat embryos in developmental toxicity studies. This also means that both embryo proper and yolk sac membrane can be used for proteomics by 2-DE when their sexing is necessary. If embryonic 2-DE samples require cleanup treatments, such as protein precipitation and nucleic acid removal (Rabilloud and Chevallet, 1999), they should be aliquoted after lysis but before these treatments, because the sexing by PCR can be performed with a very small amount of embryonic samples.

The present sexing method consists of desalting, DNA extraction and PCR. The desalting with spin columns effectively removes constituents of the 2-DE lysis buff- 


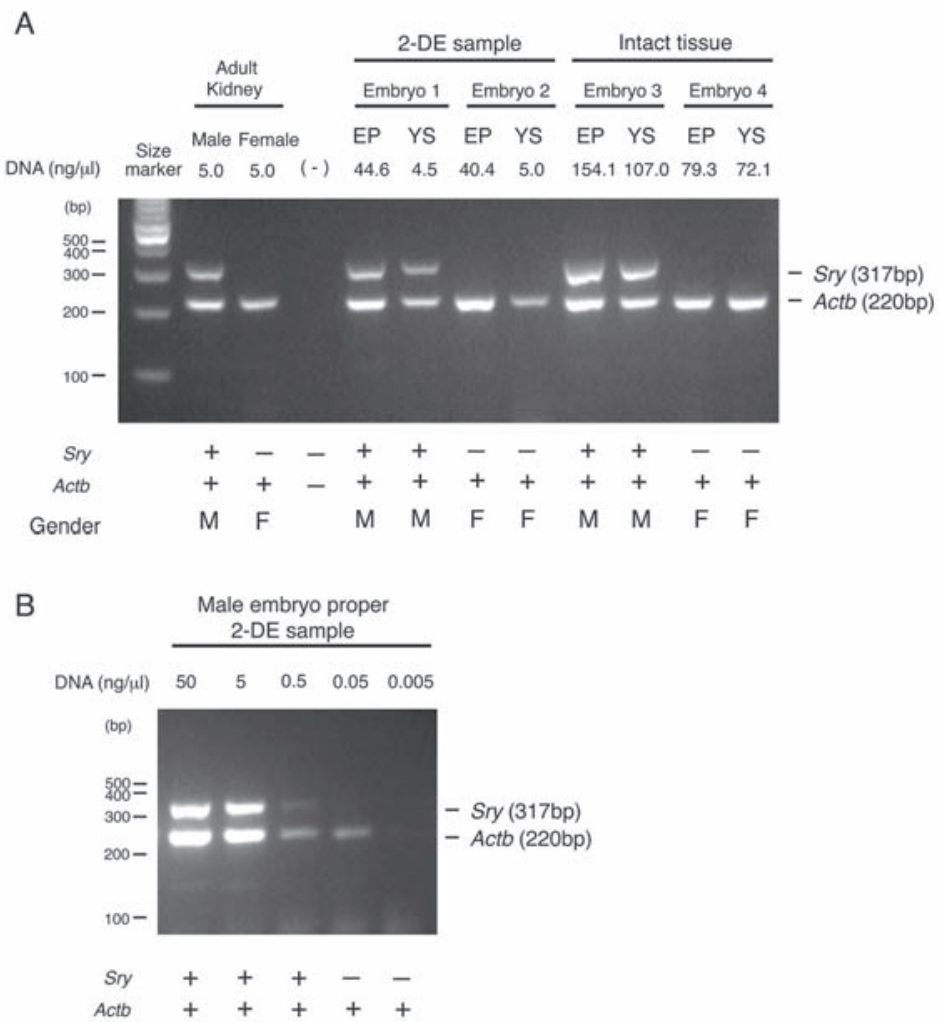

Fig. 1. Analysis of PCR products by agarose gel electrophoresis. (A) PCR products from embryonic 2-DE samples and intact tissues. Male and female adult kidneys were used as a reference. EP, embryo proper; YS, yolk sac membrane; M, male; F, Female. (B) PCR products from a serially diluted male embryo proper 2-DE sample.

Table 2. Consistency between embryonic genders determined with samples from the embryo proper and yolk sac membrane

\begin{tabular}{llcc}
\hline & & \multicolumn{2}{c}{ Yolk sac membrane } \\
\cline { 3 - 4 } & & Male & Female \\
\hline Embryo proper & Male & 14 & 0 \\
& Female & 0 & 19 \\
\hline
\end{tabular}

The number of embryos is shown. Consistency is statistically significant by the Fisher's exact test at $\mathrm{P}=1.22 \times 10^{-9}$.

er, which would interfere subsequent DNA extraction, from embryonic 2-DE samples stored after the analyses. Use of a DNA extraction kit makes this method convenient for many samples. The robustness of the present PCR procedure for a wide range of DNA concentrations obviates procedures for concentration adjustment. Thus, the present method is suitable for sexing of embryonic 2-DE samples in developmental toxicity studies, where many samples need to be processed.

For DNA extraction, a rapid method for PCR-sexing of embryos has been reported in mice (McClive and Sinclair, 2001), and the same method may be applicable in rats. We used, instead, a DNA extraction kit, which is considered to be a basis for the robustness of subsequent PCR because of higher purity of DNA. The use of a DNA extraction kit will also make it easier to perform the method in developmental toxicology studies since its protocol is well established.

\section{ACKNOWLEDGEMENTS}

This work was partially supported by the Ministry of Education, Science, Sports and Culture, Grant-in-Aid for Exploratory Research, 15658090, 2003-2005.

\section{REFERENCES}

Chen, X., Watkins, R., Delot, E., Reliene, R., Schiestl, R.H., 
Sexing of rat embryonic 2-DE samples

Burgoyne, P.S. and Arnold, A.P. (2008): Sex difference in neural tube defects in p53-null mice is caused by differences in the complement of X not Y genes. Dev. Neurobiol., 68, 265-273.

Hunter, R.H.F. (1995): Differentiation of the gonads. In: Sex determination, differentiation, and intersexuality in placental mammals. pp.69-106, Cambridge University Press, Cambridge.

Malek, F.A., Möritz, K.U., Fänghanel, J. and Bienengräber, V. (2003): Sex-related differences in procarbazine-induced cleft palate and microgenia and the anti-teratogenic effect of prenatal folic acid supplementation in rats. Ann. Anat., 185, 465-470.

McClive, P.J. and Sinclair, A.H. (2001): Rapid DNA extraction and PCR-sexing of mouse embryos. Mol. Reprod. Dev., 60, 225226.

Nguon, K., Baxter, M.G. and Sajdel-Sulkowska, E.M. (2005): Perinatal exposure to polychlorinated biphenyls differentially affects cerebellar development and motor functions in male and female rat neonates. Cerebellum, 4, 112-122.

Poletti, A., Negri-Cesi, P., Rabuffetti, M., Colciago, A., Celotti, F. and Martini, L. (1998): Transient expression of the 5alphareductase type 2 isozyme in the rat brain in late fetal and early postnatal life. Endocrinology, 139, 2171-2178.

Rabilloud, T. and Chevallet, M. (1999): Solubilization of proteins in two-dimensional electrophoresis. In: Proteome research: Twodimensional gel electrophoresis and identification methods. (Rabilloud, T., ed.), pp.9-29, Springer, Berlin ; New York.

Snell, K. and Mullock, B. (1987): Post-implantation embryo culture for studies of teratogenesis. In: Biochemical toxicology: A practical approach. (Rickwood, D. and Hames, B.D. ed.), pp.83-107, IRL Press, Oxford; Washington DC.

Usami, M., Mitsunaga, K. and Nakazawa, K. (2007a): Comparative proteome analysis of the embryo proper and yolk sac membrane of day 11.5 cultured rat embryos. Birth Defects Res. B Dev. Reprod. Toxicol., 80, 383-395.

Usami, M., Mitsunaga, K. and Nakazawa, K. (2007b): Two-dimensional electrophoresis of protein from cultured postimplantation rat embryos for developmental toxicity studies. Toxicol. In Vitro, 21, 521-526.

Usami, M., Mitsunaga, K., Nakazawa, K. and Doi, O. (2008): Proteomic analysis of selenium embryotoxicity in cultured postimplantation rat embryos. Birth Defects Res. B Dev. Reprod. Toxicol., 83, 80-96.

Usami, M. and Ohno, Y. (1996): Teratogenic effects of selenium compounds on cultured postimplantation rat embryos. Teratog. Carcinog. Mutagen., 16, 27-36. 